\title{
COMUNIDADES CIENTÍFICAS LOCAIS E IMPACTO DAS PESQUISAS NA SOCIEDADE: SINERGIA ENTRE EGRESSOS DA PÓS-GRADUAÇÃO E PROTAGONISTAS SOCIAIS ${ }^{1}$
}

\author{
Ana Maria Netto Machado \\ Université International Terre Citoyenne - UiTC - Brasil \\ Vanir Peixer Lorenzini \\ Universidade do Planalto Catarinense - UNIPLAC - Brasil \\ Jaime Farias Dresch \\ Universidade do Planalto Catarinense - UNIPLAC - Brasil

\begin{abstract}
Resumo
A partir de resultados de pesquisas realizadas na última década, no contexto da pós-graduação stricto sensu, discute-se o impacto da formação pós-graduada e seus limites. Acúmulo recente de trabalhos críticos ao produtivismo acadêmico leva a refletir sobre o papel dos egressos da pós-graduação na sociedade. A expansão dos cursos de pós-graduação resultou em que muitos mestres e doutores exercem atividades distintas da docência superior, para a qual, até meados da década de 1990, tais cursos se destinavam. Nesses outros espaços não é possível reproduzir o que se aprendeu no curso. Como empregar os resultados de pesquisa em espaços laborais? A pergunta não costuma ser discutida durante a formação. Historicamente deposita-se na ciência esperanças de melhorias para a vida; porém, qual o impacto efetivo das pesquisas/publicações. O emprego de resultados de pesquisa no mundo do trabalho e nas comunidades requer processos que não foram aprendidos na pós-graduação; nela se aprende investigar sob orientação, produzir tese ou dissertação, produzir e publicar artigos, participar de eventos científicos. Se o egresso publicou em periódicos "Qualis" (de preferência internacionais e em inglês) cumpriu com as expectativas dos órgãos avaliadores/financiadores da pós-graduação. E a contribuição com a sociedade? Que benefícios têm as comunidades/regiões com a instalação em seus territórios de profissionais que aprenderam a pesquisar? Busca-se evidenciar neste trabalho a relevância de fomentar comunidades científicas locais, que criem sinergia entre egressos da pós-graduação e outros protagonistas sociais, instalados num determinado território, para impactar o desenvolvimento econômico e social.
\end{abstract}

Palavras-chave: Produtivismo acadêmico. Pós-Graduação no Brasil. Impacto da pesquisa. Comunidade Científica Local.

\section{Introduzindo o contexto: expansão do campo da pós-graduação no Brasil}

Como consequência da expansão da pós-graduação stricto sensu no Brasil nas últimas décadas, o segmento da população com formação avançada tornou-se uma importante

\footnotetext{
${ }^{1}$ Este artigo é resultado parcial de pesquisa financiada pela FAPESC (Fundação de Amparo à Pesquisa e Inovação do Estado de Santa Catarina).
}

Barbarói, Santa Cruz do Sul, n.48, p.<9-25>, jul./dez. 2016 
categoria de trabalhadores que anteriormente não existia no Brasil, pois doutores e mestres eram exceção, faziam parte de um grupo restrito. Por um lado, configura-se a partir da referida expansão um processo de democratização do acesso a esse nível de estudos; por outro, um processo de interiorização das oportunidades que tradicionalmente estavam presentes quase que exclusivamente nos grandes polos urbanos ou capitais. Para termos uma ideia mais precisa dessa expansão, a quantidade de titulados em cursos de doutorado,

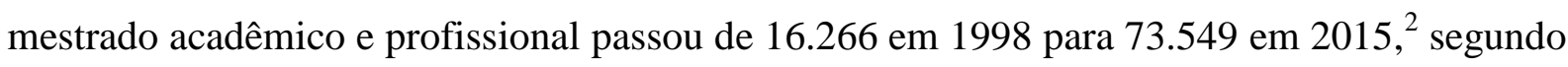
dados da Coordenação de Aperfeiçoamento de Pessoal de Nível Superior (CAPES) (BRASIL, 2016).

Em decorrência, percebe-se o surgimento de um contingente cada vez maior de egressos da pós-graduação stricto sensu (mestres e doutores) ocupando postos de trabalhos nos diferentes segmentos da sociedade; trabalhadores que aprenderam a pesquisar, sabem identificar problemas na realidade e formulá-los de maneira a buscar sua compreensão sustentada. Eles compõem um quadro de profissionais em expansão no Brasil, dos quais se pode esperar alguma contribuição para a melhoria da qualidade de vida das populações. Entretanto, a expectativa não parece estar sendo satisfeita e vem sendo muito questionada pelos pares. Qual o impacto de tantas pesquisas e publicações disponibilizadas em congressos, livros, periódicos científicos para a sociedade e, sobretudo, para as comunidades do entorno dos Programas de Pós-graduação (PPGs) instalados? Esta é uma das perguntas formuladas neste trabalho.

À medida que o número de mestres e doutores é significativo, torna-se relevante analisar quais estão sendo os efeitos dessa formação, seus impactos na sociedade. As políticas nacionais e internacionais apostam na formação avançada como estratégia para o desenvolvimento econômico das nações, postulando que dela depende também o desenvolvimento social e humano. Porém, poucos dados existem sobre o que se passa com os egressos, após a titulação. ${ }^{3}$ A própria CAPES, órgão responsável no Brasil pela avaliação e fomento do nível de formação stricto sensu, vem induzindo os Programas de Pós-graduação a implementar programas de acompanhamento de egressos durante os dois anos seguintes à obtenção do título. Porém, ainda são poucos os resultados divulgados.

\footnotetext{
${ }^{2}$ Em 1998, os cursos de Mestrado Profissional ainda não apresentavam titulados, o que ocorreu apenas no ano seguinte.

${ }^{3}$ Um outro resultado parcial da pesquisa da qual resulta este trabalho é a plataforma OVEGRESSOS Observatório de Egressos da Pós-graduação de Santa Catarina, que pode ser consultada em: www.ovegressos.com.br.
}

Barbarói, Santa Cruz do Sul, n.48, p.<9-25>, jul./dez. 2016 


\section{O Produtivismo acadêmico gera limitado impacto das pesquisas}

Crescem as publicações e debates acerca dos limites das políticas praticadas no Brasil para a pós-graduação. Alguns exemplos expressivos do debate foram publicados em número temático da revista do Sindicato Nacional dos Docentes das Instituições de Ensino Superior (ANDES), Universidade e Sociedade (2008), intitulado "Produção versus Produtivismo e precarização do trabalho". A Revista ADUSP (2009), da Associação dos Docentes da USP (ADUSP), também dedicou uma sessão inteira à questão. Duarte Jr. (2010) incluiu capítulo corrosivo em sua obra, designando os textos resultantes de indução produtivista como "rotten papers" (papéis podres, semelhantes aos causadores da recente crise financeira mundial). Bianchetti e Machado (2007) publicaram um primeiro trabalho intitulado "Reféns da Produtividade", levantando as implicações do sistema quantitativo de produção acadêmica. Outros artigos se seguiram, sendo o último dos coautores a abordar temática "A (des) fetichização do produtivismo acadêmico: desafios para o trabalhador pesquisador" (MACHADO; BIANCHETTI, 2011).

Seria possível ampliar a lista de produções voltadas ao problema, publicadas nas últimas décadas, o que é revelador da sua gravidade e do interesse despertado. Em 2013, inúmeros artigos a respeito foram publicados na Folha de São Paulo e no Jornal da Ciência, esse último órgão informativo da Sociedade Brasileira para o Progresso da Ciência (SBPC). Mais recentemente, pode-se mencionar a publicação do artigo de Kuhlmann Jr. (2015), "Produtivismo acadêmico, publicação em periódicos e qualidade das pesquisas", no qual o autor analisa os pontos críticos dos mecanismos de controle do processo de produção acadêmica.

Nesse conjunto de artigos questiona-se a qualidade das publicações que estaria sendo deixada em segundo plano em função da indução praticada pela CAPES, que estimula a quantidade de produções dos pesquisadores, punindo individualmente e também coletivamente (os Programas) se as metas não são atingidas. Também faz parte desta literatura a análise da precariedade das condições de trabalho dos pesquisadores, submetidos a exigências sobre-humanas, ${ }^{4}$ e seu impacto na saúde dos profissionais (DE MEIS et al., 2010).

\footnotetext{
${ }^{4}$ Relatórios, avaliação de artigos para periódicos, eventos e editais, trabalhos para congressos, palestras, conferências, apresentações, aulas na graduação e pós-graduação, supervisões, viagens, busca de financiamento, gestão de contas bancárias, compras de materiais com recursos financiados, reuniões, orientações, escrita, leituras, organização de dados para alimentar o Sistema Coleta CAPES, atualização frequente do Currículo Lattes são alguns itens do inesgotável rol de tarefas esperadas de um pesquisador. Um termo que podemos usar para designar este rol é "tecnoburocracia".
}

Barbarói, Santa Cruz do Sul, n.48, p.<9-25>, jul./dez. 2016 
O contingente da Pós-graduação foi convocado a cumprir metas que, em princípio, não foram programadas nem previstas pelas universidades. Dispositivos de controle, premiação e punição foram implementados, gerando rapidamente uma "performance" espetacular em tempo recorde, com números visíveis internacionalmente $(2 \%$ da produção mundial de papers), orgulho das autoridades.

O produtivismo acadêmico, na materialidade do paper, foi erigido a fetichemercadoria-conhecimento (TREIN, RODRIGUES, 2011) e, em ritmo de "Tempos Modernos", transformou os intelectuais em estressados, medicados, eficientes operários de alto padrão, seres "sem tempo" para a principal atribuição: analisar com rigor crítico a complexidade dos processos em curso (naturais ou sociais), possibilitando descortinar a lógica subjacente que comanda o espetáculo da história.

Em suma, o produtivismo acadêmico vem sendo pesquisado, denunciado, causa desconforto e provoca piadas. E em voz uníssona, nas abordagens nacionais e internacionais, o capitalismo está no banco dos réus - cada vez mais adjetivado: "capitalismo acadêmico" (SLAUGHTER, RHOADES, 2004; PARASKEVA, 2009). Cabe mencionar a consideração de Romualdo Portela de Oliveira (2015), representante da área da educação na CAPES, sobre o termo "produtivismo"; segundo ele, a crítica que tem sido feita diz respeito à "produção em quantidade". Portanto, não se defende o "improdutivismo", mas a "produção de qualidade".

Ao mesmo tempo em que se constata resignação e impotência por parte dos pesquisadores diante desse quadro, retomando o trabalho seu sentido etimológico de tripallium (instrumento de tortura), comemora-se a escalada ascendente do Brasil nos rankings internacionais de produção científica; os pares se orgulham das descobertas da ciência brasileira, que ocupa os espaços midiáticos a cada dia, envolvendo de prestígio a precária profissão da pesquisa.

\section{Qual a situação dos egressos da PG? O que deles se pode esperar?}

Os egressos do stricto sensu crescem em número aceleradamente. A partir de meados do curso de mestrado e doutorado, muitos deles passam a habitar um novo mundo, além do mundo do trabalho no qual, de modo geral, já estavam inseridos: a comunidade científica, que antes não fazia parte de seu cotidiano. O egresso passa, então, a habitar dois mundos distintos e ainda distantes em nosso país: a comunidade científica e o mundo do trabalho, na sua comunidade local/regional. Por essa dupla inserção, o egresso da PG se torna, potencialmente, um ator social estratégico para a construção de canais de comunicação e cooperação entre 
ciência e sociedade. Porém esse diálogo é complexo e o egresso não foi preparado durante o curso para praticá-lo.

Varela (2012) investigou a trajetória de egressos titulados em um PPG do interior de estado da região Sul. Entre suas conclusões figura que ao ingressar no mestrado eles estavam imbuídos de valores da cultura local a que pertencem e na qual exercem suas atividades profissionais. A partir das novas teorias que tomam conhecimento e da cultura própria da ciência e da Pós-graduação passam a ter uma nova visão do mundo, ampliada e mais sustentada da qual muito se orgulham. Ao término do curso, retornam ao seu local de trabalho (quando tiveram bolsa de estudos, por exemplo) e se deparam com colegas que não tiveram a mesma oportunidade de cursar um mestrado e produzir uma pesquisa. Pressionados pela busca de soluções imediatas, seus colegas em geral mostram dificuldade de compreender a necessidade de leituras longas e complexas, com muitas referências, não raro considerando o mestre ou doutor uma personagem pouco prática que fica no plano das ideias, desprezada como ineficaz para conduzir mudanças na realidade. Há uma distância considerável entre rotinas e valores vigentes no mundo acadêmico e aqueles mais pragmáticos do mundo do trabalho e da vida em geral. Detalhar as diferentes dinâmicas desses espaços distintos pode ajudar a pensar como aproximá-los, como diminuir a distância entre eles, a fim de criar possibilidade de cooperação entre os atores sociais com dificuldade de diálogo. Esse é o desafio que a construção de comunidades científicas locais pode ajudar a superar.

Ao escrever sobre a construção das produções científicas, Latour (2000, p. 58) destaca a importância das citações e referências na construção das ciências, afirmando que "uma monografia sem referências é como uma criança desacompanhada a caminhar pela noite de uma grande cidade: isolada, perdida, pode acontecer-lhe qualquer coisa". Quem cursou um mestrado toma consciência de como é demorado e requer esforço e dedicação referenciar um texto para que fique fundamentado. Aos poucos se constrói a paciência requerida.

Mas, uma vez que o egresso da PG está de volta ao mundo do trabalho, é incontornável deparar-se com a dificuldade de diálogo com colegas e chefias que não podem abandonar o imediatismo do pensamento da urgência.

Quem não participou desse tipo de formação muitas vezes não é sensível aos dizeres do egresso. O Mestre fala de um mundo desconhecido, em que a palavra, as ideias, os livros, a leitura e a escrita têm uma importância que pode não ser percebida (e em geral não é percebida) pela maioria dos colegas de trabalho. A não ser que também tenham participado de uma formação de mestrado. O egresso passa a ter então uma dupla existência, que precisa compatibilizar e compartilhar [...]. Um desafio cujos caminhos não foram aprendidos no mestrado e é preciso construir (VARELA, 2012). 
Um espaço para conversação é preciso e as comunidades científicas locais podem se constituir como tal. A iniciativa de promover essas comunidades poderia partir dos egressos da PG em seus espaços laborais. Porém, somente tenderão a fazê-lo aqueles que tomarem consciência dessa necessidade. Promover essa consciência seria, neste contexto, uma importante função da formação nos mestrados e doutorados.

Esta necessidade se relaciona com o fato de que é fundamental que os resultados de pesquisas acadêmico-científicas cheguem às mãos e mentes daqueles que detêm o poder de tomar decisões de interesse público que, em geral no Brasil, não são acadêmicos com mestrado ou doutorado. Levar em conta os resultados das pesquisas pode aprimorar os processos e serviços oferecidos à população, fazendo a convergência entre o trabalho dos pesquisadores e o dos políticos, entre outros, para benefício de todos.

Entretanto, esta passagem da teoria à ação (classicamente, falar-se-ia em ciência aplicada; mais recentemente fala-se em transferência de conhecimentos) não está garantida pelo fato de se ter acesso ao conhecimento científico, a conceitos, leituras, teorias e reconhecer o seu valor. A distância existente entre os conceitos (complexos e muito demorados para serem construídos) e a vida prática ${ }^{5}$ (com seu ritmo rápido) e a experiência de senso comum, pode ser tão grande que torne incomunicáveis os dois mundos. Esse problema está posto para os egressos, que passam a habitar esses dois mundos e estão desafiados a realizar essa conexão, essa ponte ou essa tradução. Gerar impacto da pesquisa na sociedade passa pela instrumentalização dos egressos para operar estas mediações, sendo insuficiente publicar papers nos melhores periódicos nacionais ou estrangeiros, mesmo que legitimados pelo sistema Qualis de avaliação de periódicos.

\section{Impacto da pesquisa na sociedade: para além das publicações, os interesses econômicos}

Anteriormente, foram abordados, entre outros aspectos, os limites da noção de impacto da pesquisa medido pelas publicações. Os resultados de pesquisa podem contribuir mais diretamente em muitos casos com os processos da sociedade, embora sempre estejam mediados pela publicação de seus resultados. Porém, apenas publicações não garantem que seus conteúdos cheguem ao conhecimento daqueles que os necessitam para tomar decisões.

\footnotetext{
${ }^{5}$ A valorização das questões práticas, aliada à pouca valorização do intelecto está ainda presente em regiões do interior brasileiro, sendo a presença local da formação em nível de Mestrado um fato novo que poderá vir a transformar essa visão.
}

Barbarói, Santa Cruz do Sul, n.48, p.<9-25>,jul./dez. 2016 
Há décadas vem se construindo consensos mundiais sobre a importância da educação e da ciência para o desenvolvimento econômico e social. A crença na ciência como esperança de melhoria de vida para as populações do mundo inteiro persiste e ainda é pouco passível de questionamento para a maioria da população, embora muitos autores tenham apontado que se trata muito mais de uma visão mítica ${ }^{6}$ do que real (SCHWARTZMAN, 2008; BOURDIEU, 1976), ou não passa de uma retórica ${ }^{7}$ que apesar de vazia convence.

Por trás do avanço dessas teses e consensos mundiais, esteve, e ainda está, nos bastidores, o interesse dos setores produtivos (empresariais, industriais), muitas vezes dissimulados entre nobres metas humanitárias (PARASKEVA, 2009), resultando na mercadorização da educação e da pesquisa. Nem novo nem recente, o interesse das empresas pelo conhecimento científico esteve presente já no final do século XVIII, quando a ciência já produzia para a indústria nascente (Europa), no decorrer da revolução industrial, como mostra Hobsbawm:

\begin{abstract}
As ciências, ainda não divididas pelo academicismo do século XIX em uma ciência "pura" superior e uma outra "aplicada" inferior, dedicavam-se à solução de problemas produtivos, e os mais surpreendentes avanços da década de 1780 foram na química, que era por tradição muito intimamente ligada à prática de laboratório e às necessidades da indústria. A grande Enciclopédia de Diderot e d'Alambert não era simplesmente um compêndio do pensamento político e social progressista, mas do progresso científico e tecnológico. Pois, de fato, o "iluminismo", a convicção no progresso do conhecimento humano, na racionalidade, na riqueza e no controle sobre a natureza - de que estava profundamente imbuído o século XVIII - derivou sua força primordialmente do evidente progresso da produção, do comércio e da racionalidade econômica e científica que se acreditava estar associada a ambos (HOBSBAWM, 2010, p. 47. Grifos no original).
\end{abstract}

\section{É interessante observar nessa passagem que o Iluminismo - frequentemente} considerado um nobre movimento erudito e cultural - está perpassado por uma série de

\footnotetext{
${ }^{6}$ Temos em preparação um artigo sobre as noções, em construção por intelectuais indígenas da América do Sul, de Sumak Kawsay e Suma Qamaña, expressões em língua quéchua e aymara (respectivamente do Equador e da Bolívia; tais etnias estão presentes também em outros atuais países), que vêm sendo traduzidas por bem viver ou viver bem. Ancoradas na cosmologia andina, estas noções se propõem como alternativas à ideia de desenvolvimento, conceito comprometido com a ideia moderna de progresso continuado, numa perspectiva de linha do tempo sem limites, em que necessariamente as nações se ordenam como mais ou menos civilizadas. As práticas societárias justificadas por esta concepção de progresso que vigora no sistema-mundo têm resultado nos problemas críticos que ameaçam a humanidade, por meio das catástrofes climáticas e problemas ambientais associados à produção e consumo predatórios, por sua vez relacionados ao aumento da pobreza no mundo. A crença no progresso, alimentado pelos progressos científicos que até o século XX não geravam grandes questionamentos, parece entrar em colapso e revelar-se cada vez mais uma retórica sem correspondência na realidade, isto é, ilusória. Estes estudos fornecem conteúdos ricos, novos e promissores para compreender o mito ao qual se refere Schwartzmann (2008). A investigação sobre o bem viver e viver bem se enquadra nos estudos descoloniais que empreendemos presentemente.

${ }^{7}$ Esta última percepção vem, sobretudo, dos autores da vertente descolonial, sendo um deles Walter Mignolo (2010).
}

Barbarói, Santa Cruz do Sul, n.48, p.<9-25>, jul./dez. 2016 
processos que lhe são mais ou menos contemporâneos na Europa, resultando em alianças entre ciência e interesses financeiros da época; perceber essas relações permite desmascarar a difundida ideia de ciência como busca desinteressada da verdade, concepção sustentada, mais do que nada, pelos mitos referidos acima (SCHWARTZMAN, 2008; BOURDIEU, 1976).

As relações entre universidade, ciência e sociedade são complexas na atualidade e sofreram transformações ao longo da história do Ocidente. Tanto a universidade, instituição quase milenar, como a ciência, que teve avanços incalculáveis durante o século XX e, sobretudo, a partir de meados do século XX, incidiram uma sobre a outra de distintas maneiras.

No Brasil, onde as universidades foram tardias, instaladas apenas no século XX (MACHADO; MENDES, 2009), a formação de docentes tornou-se uma questão importante a ser enfrentada, já que os doutoramentos só podiam ser obtidos no exterior. Inicialmente, foi criada a CAPES, em 1951 (no mesmo ano que o Conselho Nacional de Desenvolvimento Científico e Tecnológico - CNPq), concebida e coordenada por Anísio Teixeira para “erradicar" professores não titulados que lecionavam nas poucas universidades da época (em 1945 havia cinco apenas). Somente em meados da década de 1990 é que a CAPES mudou sua meta para formação de pesquisadores (BIANCHETTI; MACHADO, 2012); logo, a formação para pesquisa é bastante recente em nosso país e se desenvolveu com muita rapidez.

A Universidade de formação profissional, em princípio, não produzia pesquisas, de modo que a relação ciência universidade era frágil. A sua nova atribuição vem de organismos que lhe são externos e como consequência de determinados "consensos" relativos à tríade educação, ciência e tecnologia, que foram construídos fora das universidades, mas trazidos para seu interior por intermédio dos governos, assessorados por organismos internacionais, tais como Banco Mundial, Fundo Monetário Internacional (FMI), Organização Mundial do Comércio (OMC), Organização para a Cooperação e Desenvolvimento Econômico (OCDE), Organização das Nações Unidas para a Educação, a Ciência e a Cultura (UNESCO), Comissão Econômica para a América Latina (CEPAL) (LANGER, 2008).

Neste sentido, percebe-se as contradições das mudanças conduzidas pela CAPES a partir da década de 1990. O controle da duração dos cursos de Mestrado e Doutorado (dois anos e quatro anos, respectivamente) foi um aspecto marcante no início deste processo. Em outras palavras, fora implantada a linha de produção para o trabalho dos intelectuaisoperários, sob a égide de um novo regime de urgência (CUNHA; LAUDARES, 2009).

Não surpreende, portanto, certa desorientação das nossas universidades, cujas comunidades de docentes entraram no produtivismo acadêmico sem ter tempo para se Barbarói, Santa Cruz do Sul, n.48, p.<9-25>, jul./dez. 2016 
questionar e refletir criticamente sobre tais mudanças e suas consequências, especialmente sobre o que entendemos deva ser o impacto dos resultados de pesquisa fomentado no sistema de PG. Quem afinal vem se beneficiando do resultado do trabalho dos pesquisadores, egressos da pós-graduação? As críticas ao produtivismo acadêmico em curso são suficientemente profundas e adequadas? Oferecem uma visão alternativa em termos de concepção de impacto da pesquisa? Que valores a universidade pode, deve e deseja priorizar? Quais interesses e de quem a universidade vai priorizar? A "busca desinteressada" de outrora parece ter perdido validade e é preciso que a Universidade se posicione. Buscando clarear a discussão, Frigotto afirma que:

[...] a questão não é de se negar o progresso técnico, o avanço do conhecimento, os processos educativos e de qualificação ou simplesmente fixar-se no plano das perspectivas da resistência nem de se identificar nas novas demandas dos homens de negócio uma postura dominantemente maquiavélica ou, efetivamente uma preocupação humanitária, mas de disputar concretamente o controle hegemônico do progresso técnico, do avanço do conhecimento e da qualificação, arrancá-los da esfera privada e da lógica da exclusão e submetê-los ao controle democrático da esfera pública para potenciar a satisfação das necessidades humanas (FRIGOTTO, 1994, p. 36).

A formulação de Frigotto pode servir de bússola para os trabalhadores-pesquisadores e os PPGs, para pensar sobre a responsabilidade dos egressos da Pós-graduação, isto é, os mestres e doutores titulados pelo sistema, com relação ao aprimoramento da sociedade, no sentido da produção de uma ciência a serviço das necessidades humanas, que cabe à instituição universidade considerar. A estratégia de fomentar comunidades científicas locais favorece a identificação, por parte daqueles que pesquisaram problemas de seu entorno social, das necessidades humanas do território que habita. É, entretanto, condição para tal empreendimento, o reconhecimento dos sujeitos e do valor de seus conhecimentos e saberes que, estando presentes num determinado território, podem ser compartilhados, gerando cooperação, a fim de que os resultados de pesquisa possam contribuir para as necessárias realizações. Escutas da polifonia de vozes das comunidades são essenciais para tal.

\section{Para concluir: a relevância de fomentar Comunidades Científicas locais}

O compartilhamento dos resultados das pesquisas acadêmico-científicas entre pares, egressos da pós-graduação (mestres e doutores) e protagonistas da sociedade local, poderá fomentar um viveiro de projetos com novas parcerias, revitalização e ampliação de redes, grupos e linhas de pesquisa, e expandindo a conexão com os setores sociais e produtivos. 
Compartilhar envolve complexo processo de múltiplos reconhecimentos dos protagonistas dos diferentes segmentos da sociedade (MACHADO; LORENZINI, 2012). Esse é um ponto nevrálgico para os fins pretendidos.

Considerar a possibilidade de que o conhecimento legitimado no meio científico possa entrar na circulação pública local, dando visibilidade às descobertas realizadas por aqueles que tiveram a oportunidade de pesquisar, estabelecer pontes e conexões entre a realidade (os problemas do entorno) e os estudos e pesquisas nacionais ou internacionais, poderá estreitar a relação entre a sociedade (com seus problemas, que requerem soluções) e a comunidade científica, estabelecendo uma força-tarefa para construir possibilidades de solução.

As pesquisas que resultam em dissertações ou teses são defendidas, legitimadas por pares experientes de outras instituições e os trabalhos ficam disponibilizados nos sites para o público interessado. Porém, quem é o público interessado? Como despertar o interesse daqueles que precisariam conhecer tais resultados de pesquisa, para qualificar a educação e os demais segmentos pertinentes, em âmbito local/regional? O interesse não é dado nem imediato e a paciência para ler cem páginas não está construída na comunidade regional de professores, por exemplo. Nem todos têm acesso à Internet e os que têm carecem de tempo livre para permanecer horas diante da tela de um computador ou outro artefato tecnológico conectado à rede mundial de computadores, a fim de tomar contato com pesquisas (VARELA, 2012).

Este simples raciocínio evidencia que novas ações precisam ser implementadas para que o conhecimento novo construído em diferentes locais não seja desperdiçado, e sua potência transformadora venha a se fazer ação. O pensamento de senso comum imputa à teoria ficar no âmbito das ideias, que pouco teriam a contribuir para práticas efetivas. Ledo engano! Ingenuidade! São as ideias, os conceitos que desde sempre fizeram girar o mundo! (MACHADO; LORENZINI, 2012). Entretanto, as teorias, conceitos, ideias são mantidas sob a guarda e domínio de um segmento social hierarquicamente considerado superior (elite intelectual), com circulação ampla do ponto de vista da disponibilidade na Internet, mas limitado acesso por suas características eruditas ou de formalidade acadêmica (somente para iniciados).

Esta aura de superioridade que paira sobre pesquisadores dificulta o diálogo com quem está fora do circuito acadêmico-científico, como dito anteriormente. Por isso, o reconhecimento da potência dos resultados da pesquisa, mas também da impotência dos pesquisadores para, entre eles apenas, implementarem transformações na sociedade é essencial. A utilização dos resultados de pesquisa ou sua aplicação depende do Barbarói, Santa Cruz do Sul, n.48, p.<9-25>, jul./dez. 2016 
reconhecimento de outros sujeitos individuais e/ou coletivos da sociedade, bem como a necessidade de com eles cooperar para promover realizações em prol do bem comum. Estes movimentos envolvem autoestima, estima social e construção de solidariedade, como refere Mendonça:

[...] a possibilidade de estima social está enraizada na comunidade de valores e diz respeito à apreciação das potenciais contribuições sociais e das realizações de indivíduos. Tal possibilidade está no cerne da noção de auto-estima e da construção da solidariedade (MENDONÇA, 2009, p. 3. Itálicos no original. Grifos nossos).

Vale a pena aqui retomar a expressão que Ricoeur (2006, p. 85), a propósito de um ser humano “... 'capaz' de certas realizações”, formula no sentido de que a condição de humanidade não se completa sem esse movimento que desabrocha, desenvolve o broto de promessa ou potência que se espera (a sociedade espera) de cada indivíduo. A destinação de todo ação individual estaria fadada a alguma realização no coletivo, na comunidade de pertencimento. Nesse entendimento, as clássicas querelas manifestas em dualismos e oposições toscas, entre indivíduo e sociedade, que seguidamente assumiram a forma de rivalidade e combate entre disciplinas, mostram o seu limite heurístico e sua função de entrave, tanto epistemológico quanto político. Humano seria tal movimento movido por sucessivos reconhecimentos, da esfera individual à esfera social.

O exercício dessa capacidade de fazer os acontecimentos ocorrerem no mundo físico e social se desenvolve em um regime de interação no qual o outro pode desempenhar o papel de obstáculo, de auxiliador ou de cooperador, como nas ações conjuntas, quais às vezes é impossível isolar a contribuição de cada um (RICOEUR, 2006, p. 264. Grifos nossos).

Ricoeur (2006) afirma que não há conhecimento sem reconhecimento. Para que o estudo, a busca de conhecimento não se limite a "reproduzir eternamente em palavras o que aprendemos sempre preparados para os exames", como dizia Fichte, mas revele a força das ideias (dos conceitos, das teorias), é preciso estudar e pesquisar "para aplicar o conhecimento ao que nos ocorre na vida e para transformá-lo em obras; não se trata simplesmente de reproduzir o que estudamos, mas de extrair daí algo diferente; a finalidade última não é, portanto o conhecimento, senão a arte de empregar o conhecimento" (FICHTE, 1999, p. 28). Esta "arte de empregar o conhecimento" pode ser traduzida como a capacidade de transformar a potência ou promessa, que cada indivíduo carrega em si, em realizações no âmbito da (s) coletividade (s) a que se pertence. É neste sentido que o reconhecimento mútuo pode ser fomentado entre pares que aprenderam a pesquisar, egressos de Mestrado e Doutorado instalados em determinada região ou comunidade e os atores sociais individuais e 
coletivos que não realizaram um percurso de estudos acadêmicos, mas exercem seu protagonismo nas diversas esferas da vida social e do mundo do trabalho que todos compartilham. Uma sinergia precisa ser estabelecida, para que os resultados dos estudos aprofundados (pesquisas) possam entrar em circulação entre os atores sociais, que podem aproveitá-los e pô-los em ação na busca do bem comum (BOLLIER, 2014) e do bem viver (RODRÍGUEZ; 2014).

As ideias movem o mundo. As teses e dissertações são feitas de ideias conectadas com problemas da realidade e podem voltar para ela, com uma compreensão sustentada e portadora de potenciais mudanças. Porém, a potência dessas ideias precisa ser mobilizada por sujeitos, em outros espaços da sociedade, além da esfera acadêmico-científica. Portanto, insistimos, precisa da cooperação de outros atores sociais não acadêmicos, cuja ação não está dentro das universidades. Os conhecimentos ditos científicos, produzidos na universidade, não incluem todas as condições para sua implementação. A universidade experimenta aí seus limites e sua necessidade de colaboração com protagonistas não universitários. Reconhecer esta limitação é ponto de partida para que a universidade encontre novos rumos e um lugar e papel relevantes nas sociedades do sistema mundo (WALLERSTEIN, 2006) contemporâneo.

\title{
LOCAL SCIENTIFIC COMMUNITIES AND THE IMPACT OF RESEARCH RESULTS IN SOCIETY: SYNERGIES BETWEEN MASTERS AND PHD'S AND SOCIAL ACTORS
}

\begin{abstract}
Based on results of research carried out in the last decade, in the context of Postgraduate courses (Masters and PHD). We discuss the impact of postgraduate training and its limits. Recent critical works to academic productivity leads to reflect on the role of the researchers and the impact of their work in society. The expansion of the Brazilian's system resulted in many masters and doctors performing spaces that are not higher education system, for which was oriented that training until the mid-1990s. In these other spaces it is not possible to reproduce what was learned in the course. How to employ search results in several workspaces, out of universities? The problem is not enough discussed, during training. Historically, many hopes of humanity have been expected from science, for improvements in social-well-being. The use of research results in the work posts requires processes that have not been learned in the courses; learns are about investigate under guidance, producing thesis or dissertation, papers and scientific congress. If juniors masters and PHDs publishes in excellent journals (preferably international, in English) they satisfy expectations of evaluating/funding organisms. What about contribution to society? What benefits have communities that keeps professionals that are able to research? This article seeks to explain the relevance of promoting local scientific communities, which may create synergy between professionals capable of research and other social actors installed in territory, to impact economic and social development.
\end{abstract}

Keywords: Masters and PHD courses. Academic productivism. Local scientific communities. 


\title{
COMUNIDADES CIENTÍFICAS LOCALES E IMPACTO DE LAS INVESTIGACIONES EN LA SOCIEDAD: SINERGIAS ENTRE EGRESADOS DE POSGRADO Y PROTAGONISTAS SOCIALES
}

\begin{abstract}
Resumen
A partir de resultados de investigaciones realizadas en la última década en el contexto de Posgrado brasileño (PG), discutimos el impacto de este nivel de formación y sus límites. Recientes trabajos críticos al productivismo académico llevan a reflexionar sobre el papel de los egresados de PG en la sociedad. La expansión del sistema resultó en que muchos mestres y doctores actúen en actividades fuera de la universidad. Hasta mitad de los 1990, el PG calificaba profesores para la universidad. En otros espacios laborales no es posible reproducir lo que se aprendió en el curso de PG. Como utilizar los resultados de las investigaciones en los demás espacios sociales es una pregunta que prácticamente no se presenta durante la formación. Se ha depositado en la ciencia esperanzas de una vida mejor; pero, cual ha sido el impacto efectivo de las publicaciones? La aplicación de resultados de investigación en el mundo del trabajo requiere más que publicaciones, procesos que no se aprendieron en el PG; en este se aprende a investigar con orientación, a producir tesis, publicar artículos, participar en eventos científicos. Si el egresado publica en periódicos prestigiosos, en inglés, cumplió con las expectativas de los órganos evaluadores de PG. Y como se colabora con la sociedad? Que beneficios tienen las comunidades con la presencia de profesionales que pesquisan? Intentamos evidenciar la relevancia en fomentar comunidades científicas locales, que creen sinergias entre los egresados de PG y otros protagonistas sociales del territorio, para impactar el desarrollo económico y social.
\end{abstract}

Palabras clave: Posgrado. Productivismo académico. Comunidad científica local.

\section{Referências}

BIANCHETTI, L; MACHADO, A. M. N. "Reféns da produtividade": sobre produção do conhecimento, saúde dos pesquisadores e intensificação do trabalho na pós-graduação. 2007. Trabalho apresentado na XXX Reunião Anual da ANPEd, 2007. Disponível em: <http://30reuniao.anped.org.br/trabalhos/GT09-3503--Int.pdf >. Acesso em: 25 nov. 2016.

A bússola do escrever: desafios e estratégias na escrita e orientação de teses e dissertações. São Paulo: Cortez, 2012.

BOLLIER, David. La rennaissance des Communs: Pour une société de coopération et de partage. Paris : Éditions Charles Léopold Mayer, 2014.

BOURDIEU. Pierre. Le champ scientifique. Actes de la recherche en sciences sociales, v. 2, n. 2-3, p. 88-104, jun. 1976. Disponível em: <http://www.persee.fr/doc/arss_03355322_1976_num_2_2_3454>. Acesso em: 25 nov. 2016.

BRASIL. Ministério da Ciência, Tecnologia e Inovação. Indicadores sobre o ensino de pósgraduação. Disponível em: <http://www.mct.gov.br/index.php/content/view/6629.html >. Acesso em: 25 nov. 2016. 
DE MEIS, L.; VELlOSO, A.; LANNES, D.; CARMO, M. S.; DE MEIS, C. The growing competition in Brazilian science: rites of passage, stress and burnout. Brazilian Journal of Medical and Biological Research, Ribeirão Preto, v. 36, n. 9, p. 1135-1141, set. 2003.

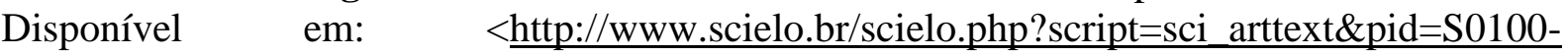
879X2003000900001\&lng=en\&nrm=iso>. Acesso em: 25 nov. 2016.

CUNHA, D. M; LAUDARES, J. B. Trabalho: diálogos multidisciplinares. Belo Horizonte: UFMG, 2009.

DUARTE JR. João Francisco. The rotten papers (ou adiós que yo me voy). In: DUARTE JR. A montanha e o videogame: escritos sobre educação. Campinas: Papirus, 2010.

ELIAS, Norbert. Escritos \& ensaios: 1- Estado, processo, opinião pública. Organização e apresentação Federico Neiburg e Leopoldo Waizbort; Tradução Sérgio Benevides, Antonio Carlos dos Santos, João Carlos Pijnappel. Rio de Janeiro: Jorge Zahar, 2006.

FICHTE, Johann Gottlieb. Por uma universidade orgânica: plano dedutivo de uma instituição de ensino superior a ser edificada em Berlim, que esteja estreitamente associada a uma Academia de Ciências. Organização Joao Cezar de Castro Rocha, Johannes Kretschmer; tradução e introdução Johanes Kretschmer. Rio de Janeiro: EdUERJ, 1999.

FRIGOTTO, G. Educação e formação humana: ajuste neo-conservador e a alternativa democrática. In: GENTILI, P; SILVA, T. T. (Orgs.). Neoliberalismo, qualidade total e educação: visões críticas. Petrópolis: Vozes, 1994.

HOBSBAWM, Eric J. A era das revoluções: 1789-1848. São Paulo: Paz e Terra, 2010.

JANTSCH, Ari Paulo. Mercadorização, formação, universidade pública e pesquisa críticoemancipatória: em tempos de realização plena do conceito de capital. In: OLIVEIRA, J. F; CATANI, A. M; SILVA JÚNIOR, J. dos R. (Org). Educação superior no Brasil: tempos de internacionalização. São Paulo: Xamã, 2010.

KUHLMANN JR., Moysés. Produtivismo acadêmico, publicação em periódicos e qualidade das pesquisas. Cadernos de Pesquisa, São Paulo, v. 45, n. 158, p.838-855, out./dez. 2015. Disponível em: $\quad<$ http://www.scielo.br/scielo.php?script=sci_arttext\&pid=S010015742015000400838>. Acesso em: 25 nov. 2016.

LANGER, Ariel. El sistema científico y las universidades: revisión de teorias y enfoques en América Latina y Argentina. In: RIQUELME, G. C. (Ed). Las universidades frente a las demandas sociales y productivas - capacidades de los grupos de docência e investigación en la producción y circulación del conocimiento. Tomo 1. Buenos Aires: Miño y D’Avila Srl; Madrid: Miño y D’Avila, 2008.

LATOUR, Bruno. Ciência em ação. São Paulo: Editora UNESP, 2000.

MACHADO, A. M. N.; BIANCHETTI, L. A (des) fetichização do produtivismo acadêmico: desafios para o trabalhador pesquisador. Revista de Administração de Empresas, vol. 51, n. 3, maio-jun 2011. Disponível em: $<$ http://www.scielo.br/scielo.php?script=sci_arttext\&pid=S003475902011000300005\&lng=pt\&nrm=iso >. Acesso em: 25 nov. 2016. 
.; LORENZINI, V. Pluri-Reconhecimentos sucessivos como condição para a autorealização: da arte de transformar o conhecimento em ação. In: MACHADO, Ana Maria Netto (Org.). Toc! Toc! Toc! Eu quero entrar: conhecimento e reconhecimento de egressos do stricto sensu. Florianópolis: DIOESC, 2012.

; MENDES, V. H. Universidades comunitárias do sul do Brasil no cenário e na história da (s) universidade (s): a centralidade do problema da autonomia e os processos de interiorização e universalização da educação superior. In: NUNES, A. K. (Org.). Universidade comunitária e avaliação: os quinze anos do PAIUNG. Santa Cruz do Sul: EDUNISC, 2009.

MENDONÇA, Ricardo Fabrino. Dimensão intersubjetiva da auto-realização: em defesa da teoria do reconhecimento. Revista Brasileira de Ciências Sociais, São Paulo, v. 24, n. 70, jun. 2009. Disponível em: <http://www.scielo.br/scielo.php?script=sci_arttext\&pid=S010269092009000200009\&lng=en\&nrm=iso>. Acesso em: 25 nov. 2016.

MIGNOLO, Walter. Desobediencia Epistémica: Retórica de la Modernidad, Lógica de la Colonialidad y Gramática de la Descolonialidad. Buenos Aires: Ediciones del Signo, 2010.

Disponível em: https://antropologiadeoutraforma.files.wordpress.com/2013/04/mignolowalter-desobediencia-epistc3a9mica-buenos-aires-ediciones-del-signo-2010.pdf Acesso em 23 jun. 2017.

OLIVEIRA, Romualdo Portela. Entrevista. Portal da ANPEd, 11 mar. 2015. Disponível em: <http://www.anped.org.br/news/entrevista-prof-romualdo-portela-representante-da-area-deeducacao-na-capes>. Acesso em: 25 nov. 2016.

PARASKEVA, João M. (Org.). Capitalismo académico. Mangualde: Edições Pedago, 2009.

RICOEUR, Paul. Percurso do reconhecimento. Tradução Nicolás Nyimi Campanário. São Paulo: Edições Loyola, 2006.

RODRÍGUEZ, Edwin, Cruz. Prolegómenos al vivir bien-buen vivir: una evaluación normativa y práctica. Revista Finanz., Polít., Econ., vol. 6, núm. 2, julio-diciembre, 2014, pp. 387-402. Universidad Católica de Colombia, Bogotá D.C., Colombia. Disponível em: http://www.redalyc.org/pdf/3235/323532046007.pdf. Acesso em 23 junho 2017.

SCHWARTZMAN, Simon. Ciência, universidade e ideologia. Rio de Janeiro: Centro Eldestein de Pesquisas Científicas, 2008.

SLAUGHTER, S.; RHOADES, G. Academic Capitalism and the New Economy: markets, state and higher education. Baltimore: John Hopkins University Press, 2004.

TREIN, E.; RODRIGUES, J. O mal-estar na academia: produtivismo científico, o fetichismo do conhecimento-mercadoria. Revista Brasileira de Educação, Rio de Janeiro, v. 16, n. 48, p. 769-792, dez. 2011. Disponível em: $<$ http://www.scielo.br/scielo.php?script=sci_arttext\&pid=S141324782011000300012\&lng=en\&nrm=iso >. Acesso em: 25 nov. 2016. 
VARELA, Abel. Sou mestre... e daí? Formação stricto sensu e desenvolvimento: um estudo da mobilidade profissional, atuação e perspectivas de impacto regional dos egressos dos PPGs da UNIPLAC. In: MACHADO, Ana Maria Netto Machado (Org.). Toc! Toc! Toc! Eu quero entrar: conhecimento e reconhecimento de egressos do stricto sensu. Florianópolis: DIOESC, 2012. p. 267-283.

WALLERSTEIN, I. Impensar a ciência social: os limites dos paradigmas do século XXI. São Paulo: Ideias \& Letras, 2006.

\section{BIBLIOGRAFIA CONSULTADA:}

UNIVERSIDADE E SOCIEDADE, Brasília, v. XVII, n. 41, jan. 2008. Disponível em: $<$ http://portal.andes.org.br/imprensa/publicacoes/imp-pub-289306753.pdf $>$. Acesso em: 25 nov. 2016.

REVISTA ADUSP, São Paulo, n. 45, out. 2009. Disponível em: $<$ http://www.adusp.org.br/index.php/imprensa/revista-adusp/126-revista-n-45-outubro-de2009>. Acesso em: 25 nov. 2016.

Data de recebimento: $27 / 11 / 2016$

Data de aceite: 14/06/2017

\section{Sobre os autores:}

Ana Maria Netto Machado é Graduada em Psicologia, Mestre e Doutora em Educação pela UFRGS e doutora em Ciências da Linguagem pela Université de Paris X (Nanterre/França); a partir de 1995 atuou, sucessivamente, em PPGEs emergentes, em universidades comunitárias dos três estados do sul do Brasil, interessando-se pela interiorização da Pós-graduação (PG) no país. Escrita, autoria, orientação de teses e dissertações, modelos de universidade, cultura da pós-graduação, crítica ao produtivismo acadêmico, protagonismo dos egressos da PG e a relação entre a universidade e a sociedade são temas sobre os quais pesquisou/publicou. De 03/2004 a 07/2017 atuou no PPGE da Universidade do Planalto Catarinense-UNIPLAC (Lages/SC), cuja construção do projeto liderou, sendo o curso recomendado pela CAPES na primeira submissão (2008). Integra a Université International Terre Citoyenne (www.uitcedu.org) e atualmente revisita sua produção sob a perspectiva descolonial. Endereço Eletrônico: laborescrita@gmail.com

Vanir Peixer Lorenzini é Mestre em Educação pela Universidade do Planalto Catarinense (UNIPLAC), direcionando sua pesquisa para as práticas pedagógicas diante da inclusão escolar de pessoas com deficiência. Especialista em Educação Especial, Psicopedagogia e Psicomotricidade. Pedagoga, com habilitação em Supervisão Escolar. Atuou como professora em instituição de educação especial entre os anos de 1970 a 1995. Atualmente é professora concursada da UNIPLAC com atuação no ensino, extensão e pesquisa, especialmente em relação à inclusão e acessibilidade educacional. Integra a Comissão Institucional de Acessibilidade da UNIPLAC e a Comissão de Inserção de Pessoas com Deficiência no 
Quadro Funcional desta Instituição. É Membro do Conselho Municipal dos Direitos da Pessoa com Deficiência (COMPED) do município de Lages (SC). Membro (suplente) do Conselho Universitário da UNIPLAC. Endereço Eletrônico: vanirlp@ gmail.com

Jaime Farias Dresch é Doutor em Educação (UFSCar), com período de estágio no exterior, realizado no Instituto de Educação da Universidade do Minho, em Portugal. Mestre em Educação (UNESP-Rio Claro). Pedagogo (UNESP-Rio Claro). Professor do Programa de Pós-Graduação em Educação da Universidade do Planalto Catarinense (UNIPLAC). Atuou como professor da Educação Básica, nas séries iniciais. Atuou como professor substituto na UNESP e como professor do Curso de Pós-Graduação Lato Sensu em Coordenação Pedagógica na UFSCar. Experiência na área de Educação, com ênfase em Políticas Educacionais, atuando principalmente nos seguintes temas: Estado e políticas educacionais para a Educação Básica e para o Ensino Superior; Avaliação da educação; Imprensa, comunicação, discursos e relações de poder no âmbito educacional. Endereço Eletrônico: jaimefariasdresch@gmail.com 